\title{
A Clinical Study to Evaluate Ocular Manifestations of Trauma
}

\author{
Dr. Hendge Ramchandra Dattatray ${ }^{1}$, Dr. Jawahar J. Kuli ${ }^{2}$, Dr. Rajendra N. Gogoi ${ }^{3}$ \\ ${ }^{1,2,3}$ Department of Ophthalmology, Assam Medical College, Dibrugarh, India
}

\begin{abstract}
Purpose: To evaluate the ocular manifestations of trauma. Setting: Assam Medical College \& Hospital, Dibrugarh. Study design: Hospital based observational study. Patients and Methods: All patients with ocular injuries attending casualty and ophthalmology department were included in this study. A thorough systematic examination was done. Severely injured patients not fit for complete examination were excluded from the study. The data was collected and tabulated to draw the inferences. There were no controls in our study. Conclusion: Ocular trauma patients have varying degree of blurring and diminution of vision. $60 \%$ patients had visual acuity better than 6/12.Sub conjuctival haemorrhage(60\%) was the most common eye finding followed by peri orbital ecchymosis(40\%).
\end{abstract}

Keywords: Ocular trauma, eye injuries, black eyes, subsconjunctival hemorrhage

\section{Introduction}

Worldwide, trauma is the major cause of uni-ocular blindness and second leading cause of blindness (1). In the Indian context, ocular injuries constitute $1.5 \%$ of total blindness. Illiteracy, ignorance \& low socio economic status contribute in a big way in ocular morbidity (2). Trauma is not restricted to any age, sex or regional groups, still more common in young males (3). Road traffic accidents are major problems in our country. Other incidences are - sports, household injuries, physical assaults, occupational injuries etc. (4).

\section{Materials \& Methods}

\subsection{Aims \& Objectives:}

The aims of the study were:

1) To determine the ocular manifestations of trauma.

2) To assess the visual acuity after ocular trauma.

\subsection{Source of Data}

All patients with ocular injuries attending casualty and Ophthalmology Department of AMCH, Dibrugarh.

\subsection{Method of Collection of Data}

The number of patients enrolled in the study was 60. All patients were evaluated thoroughly with systematic recording of nature of injury, visual acuity and other related findings. Slit lamp examination, dilated fundus examination etc. were done whenever necessary.

\subsection{Inclusion Criteria}

1) All patients with ocular injuries attending casualty and Ophthalmology Department of AMCH, Dibrugarh.

2) Both male and female

3) Age more than 5 years

\subsection{Exclusion Criteria}

1) Severely injured patients

2) Multisystem injuries

3) Age less than 5 years

4) Patients unfit for through ocular examination

\section{Results and Observations}

Table 3.1: Ocular injuries

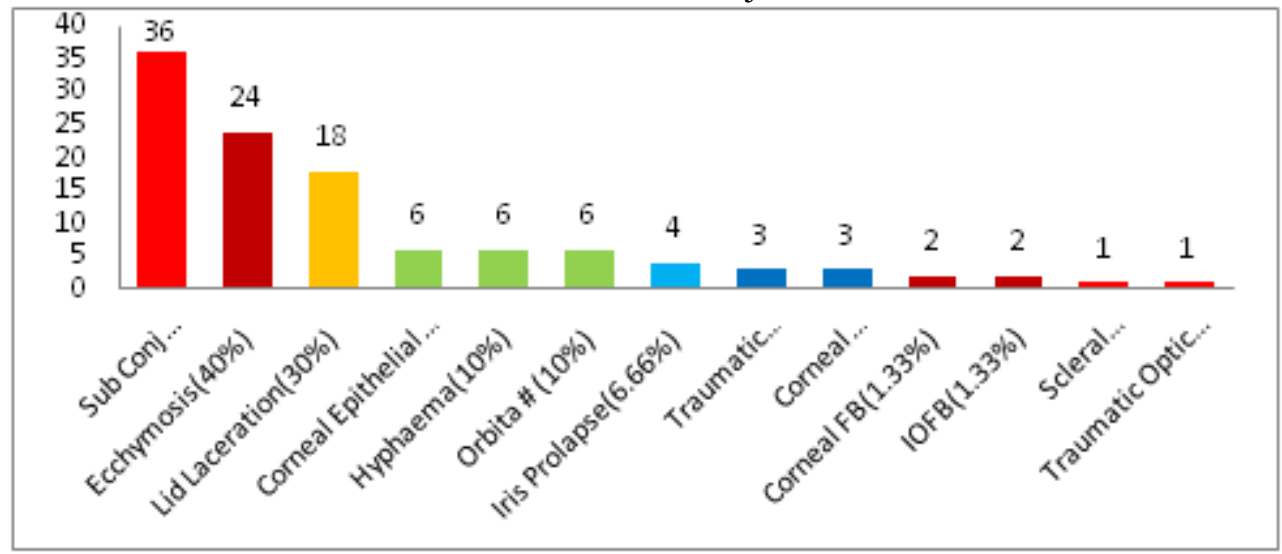




\section{International Journal of Science and Research (IJSR) \\ ISSN (Online): 2319-7064}

Index Copernicus Value (2013): 6.14 | Impact Factor (2015): 6.391

Table 3.2

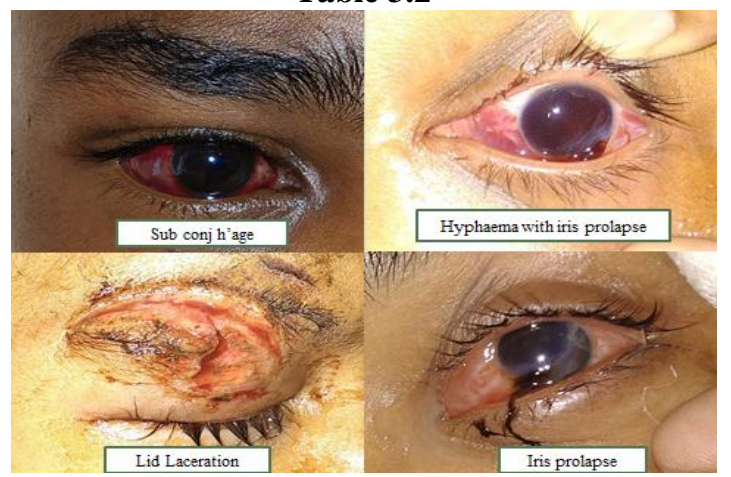

Table 3.3: Sex distribution

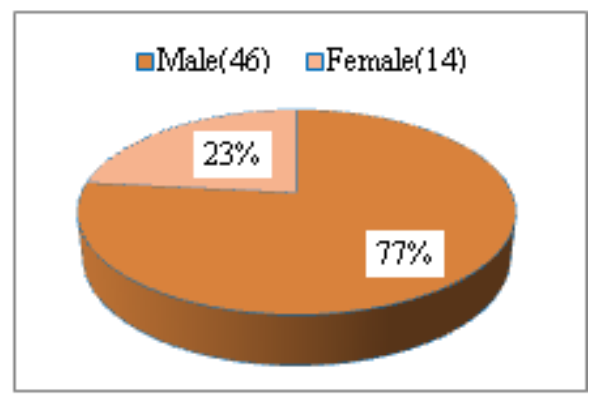

Table 3.4: Age distribution

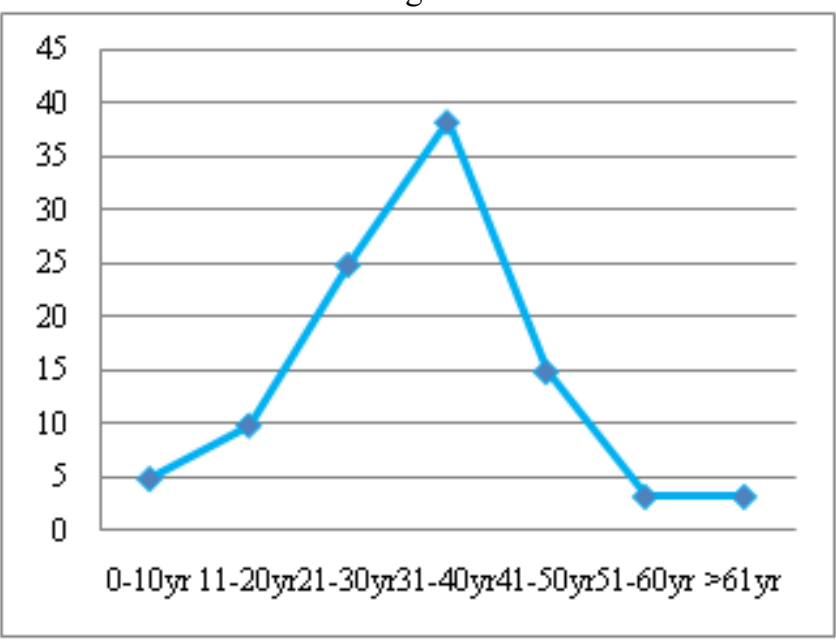

Table 3.5: Laterality of injury

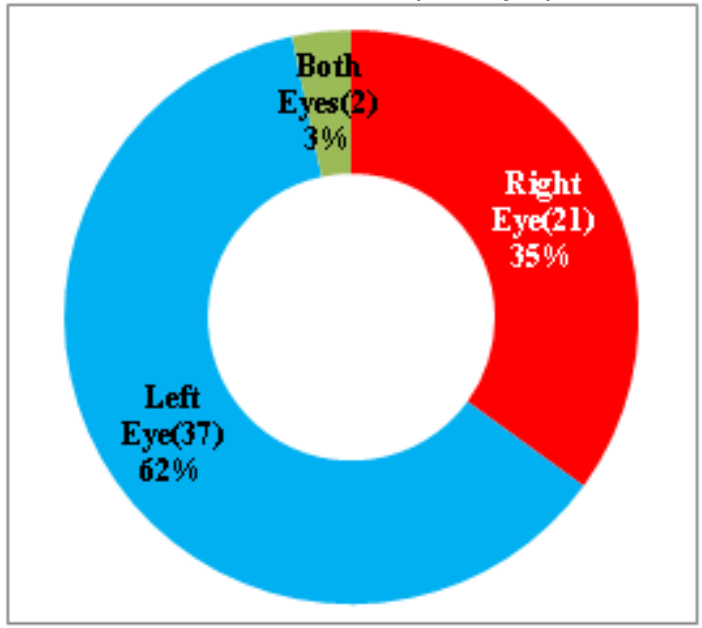

Table 3.6: Visual acuity at presentation

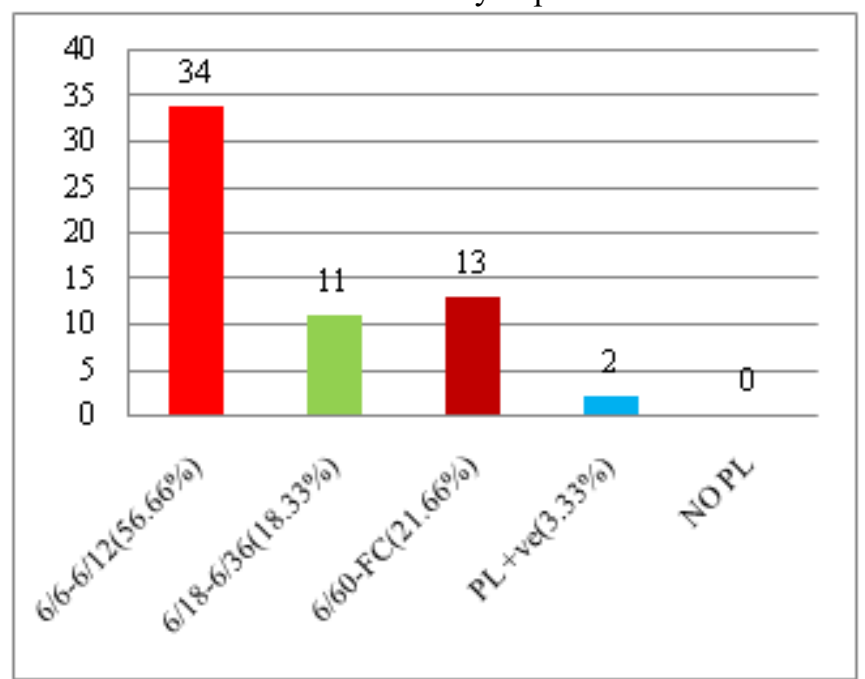

Table 3.7: Ocular manifestations $\mathrm{V} / \mathrm{s}$ visual acuity

\begin{tabular}{|l|l|l|}
\hline $\begin{array}{l}\text { Sr } \\
\text { no }\end{array}$ & Ocular Manifestation & Visual Acuity \\
\hline 1 & Sub Conj h'age(60\%) & $6 / 6-6 / 12$ \\
\hline 2 & Ecchymosis(40\% & $6 / 6-6 / 12$ \\
\hline 3 & Lid Laceration(30\%) & $6 / 6-6 / 12$ \\
\hline 4 & Hyphaema(10\%) & $6 / 12-\mathrm{PL}$ \\
\hline 5 & Corneal Epithelial Erosions(10\% & $6 / 6-6 / 18$ \\
\hline 6 & Orbital\#(10\%) & $6 / 12-6 / 36$ \\
\hline 7 & Iris Prolapse(6.66\%) & $6 / 9-6 / 60$ \\
\hline 8 & Traumatic Mydriasis(5\%) & $6 / 12-6 / 24$ \\
\hline 9 & Corneal Laceration(5\%) & $6 / 12-6 / 60$ \\
\hline 10 & Corneal FB(1.33\%) & $6 / 9-6 / 12$ \\
\hline 11 & IOFB(1.33\%) & $6 / 36$ \\
\hline 12 & Scleral Laceration(1.6\%) & $6 / 24-6 / 60$ \\
\hline 13 & Traumatic Optic Neuropathy(1.6\%) & $\mathrm{PL}+\mathrm{ve}$ \\
\hline
\end{tabular}

Table 3.8: BEETS classification

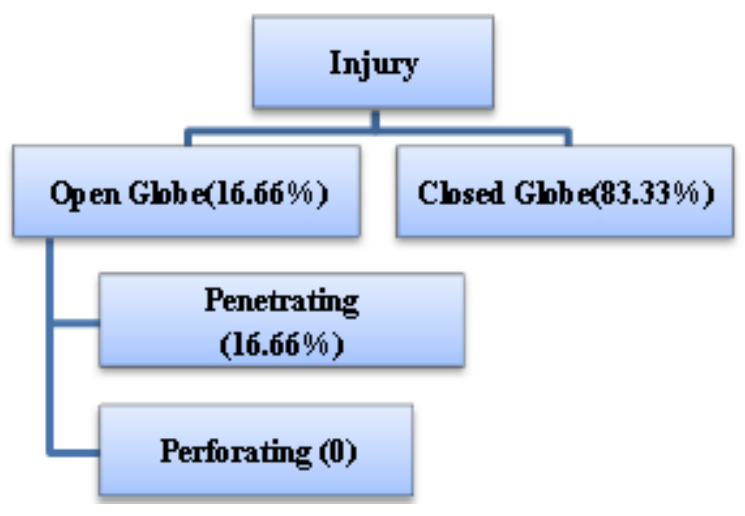




\section{International Journal of Science and Research (IJSR) \\ ISSN (Online): 2319-7064}

Index Copernicus Value (2013): 6.14 | Impact Factor (2015): 6.391

Table 3.9: Type of injury

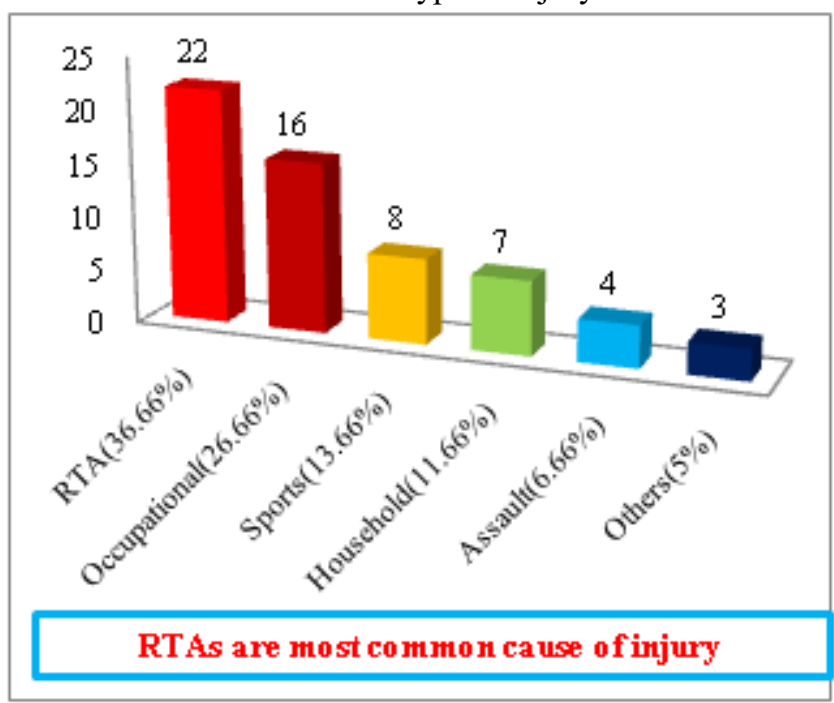

Table 3.10: Medico legal status

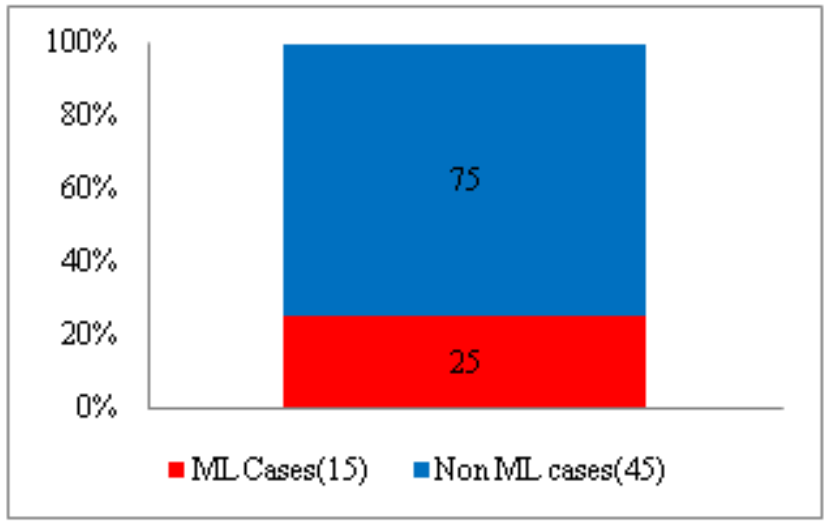

\section{Discussion}

In the Indian context ocular injury constitute $1.5 \%$ of total blindness. Illiteracy, ignorance low socio economic status contributes in a big way in ocular morbidity. Although eyes have been provided protection with bony wall and lids, still it is exposed to various forms of trauma, most of which are preventable. Ocular trauma are not restricted to any age, sex or regional group still it is more common in young males working outdoors in field. Road traffic accidents are one of the major problems in our country. It causes enormous fatalities and ocular morbidities like peri orbital ecchymosis, sub conjuctivalhemorrhage, lid laceration, corneal lacerations etc. Other incidences causing ocular injuries are - outdoor games, chemical spillage, fall on blunt objects, occupations like carpenters, welders, factory and chemical industry workers.

AmanArora et al(2011) performed a study of 150 patients of RTA. He found that males(71\%) were more commonly involved than females, Right eye (69\%) was more commonly affected and ecchymosis(83\%) was most common ocular manifestation.

SupriyaPatil et al (2008) studied total of 350 patients of RTA. They found that avarage age of victim was 32.5 years.M:F ratio was $4.6: 1$
Sub conjunctivalhaemorrhage $(60 \%)$ is the most common ocular manifestation of trauma, followed by ecchymosis $(40 \%)$, lidlaceration $(30 \%)$ and corneal lacerations $(10 \%)$ etc. Most of the ocular injuries can be avoided. Awareness and Healthy working environment can prevent ocular injuries and morbidities.

\section{References}

[1] MacCumber; Epidemiology of ocular trauma;'98

[2] NPCB;'02

[3] D V Singh; Profile of ocular trauma at tertiary eye centre;'05

[4] WHO;'04

\section{Conclusion}

